DOI: https://doi.org/10.47405/mjssh.v6i8.926

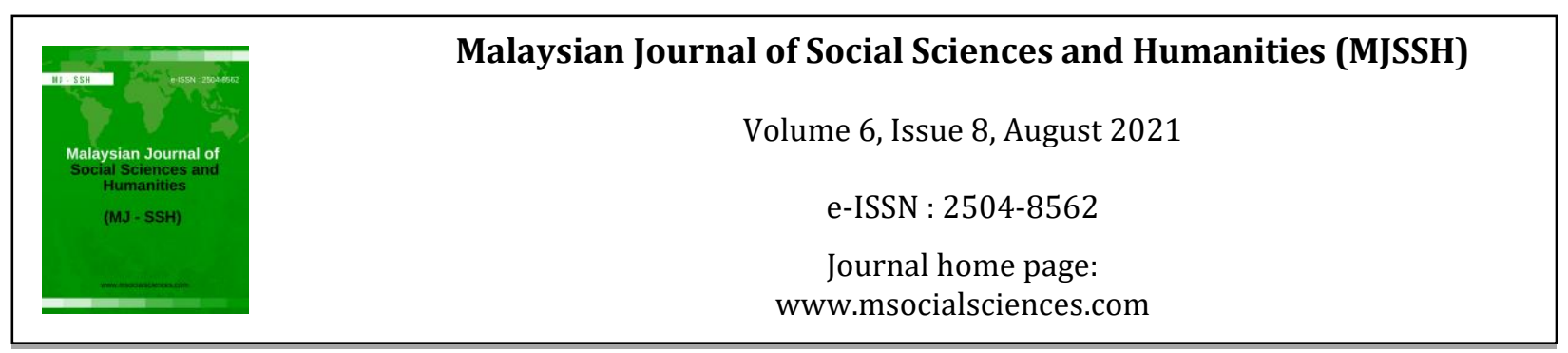

\title{
Hubungan Antara Kecerdasan Emosi dengan Prestasi Akademik Pelajar Sarjana
}

\author{
Mayurie Phutharat Surin' ${ }^{1}$, Shahlan Surat ${ }^{1}$ \\ ${ }^{1}$ Fakulti Pendidikan, Universiti Kebangsaan Malaysia (UKM) \\ Correspondence: Mayurie Phutharat Surin (mayurie.yurie@gmail.com)
}

\begin{abstract}
Abstrak
Kecerdasan emosi pelajar yang pelbagai wajar diberi perhatian kerana ia memberi kesan jangka panjang terhadap prestasi mereka. Tambahan lagi, kajian mengenai kecerdasan emosi boleh dijalankan bagi memberi panduan untuk menghasilkan pembelajaran yang berkesan. Oleh itu, kajian ini dilaksanakan untuk mengenal pasti hubungan antara kecerdasan emosi dengan prestasi akademik bagi pelajar sarjana. Kajian ini menggunakan kaedah kuantitatif yang dijalankan secara tinjauan berasaskan soal selidik yang diadaptasi dari Instrumen Inventori Kecerdasan Emosi. Seramai 121 orang pelajar dari kalangan pelajar sarjana sebuah universiti awam di Bangi terlibat dalam soal selidik ini. Analisis inferensi Kolerasi Pearson digunakan untuk menunjukkan hubungan antara kecerdasan emosi dengan prestasi akademik pelajar sarjana. Hasil kajian mendapati bahawa wujudnya hubungan yang signifikan antara kecerdasan emosi dengan prestasi akademik pelajar sarjana dengan nilai kolerasi $r=0.161$, $(p<$ $\mathrm{a}=0.05$ ). Implikasi bagi kajian ini adalah jelaslah bahawa faktor emosi merupakan antara faktor penyumbang terhadap prestasi akademik seseorang dan faktor yang mempengaruhi emosi pelajar sarjana juga wajar diberi perhatian.
\end{abstract}

Kata kunci: kecerdasan emosi, prestasi akademik, psikologi pendidikan, inventori kecerdasan emosi, pelajar sarjana

\section{The Relationship between Emotional Intelligence and Academic Performance of Master's Students}

\begin{abstract}
The diverse emotional intelligence of students deserves attention as it has a long -term impact on their performance. In addition, various emotional intelligence could be used as a guide in creating quality education as a basis for the acquisition of knowledge for a student. Therefore, this study was conducted to identify the relationship between emotional intelligence and the level of academic achievement. This study used a quantitative method through a survey based on a questionnaire adapted from the Emotional Intelligence Inventory Instrument. A total of 121 Master's students from a public university in Bangi were involved in this survey. Pearson Correlation inferential analysis was used to show the relationship between emotional intelligence and student academic achievement. The results showed that there was a significant relationship between emotional intelligence and academic achievement with a correlation value of $r=0.161,(p<a=0.05)$. This study implied that emotional factors are among the contributing factors to a person's academic achievement and emotional factors should be given their due attention.
\end{abstract}


Keywords: emotional intelligence, academic performance, educational psychology, emotional intelligence inventory, master's students

\section{Pengenalan}

Dalam sistem pendidikan, pelajar sering menghadapi kesukaran dalam menghadapi beban akademik dari segi tugasan, projek dan peperiksaan terutamanya disebabkan oleh kekurangan bimbingan yang betul, persekitaran pembelajaran yang buruk, perbezaan bahasa dan faktor sosio-ekonomi (Fakhar et al., 2021). Ini disokong oleh Sahrai (2016) yang menyatakan bahawa masalah pencapaian pendidikan adalah salah satu masalah utama pendidikan di seluruh dunia. Prestasi akademik sebenarnya dirujuk kepada kes di mana bakat individu berkembang dan pelajar melewati peringkat yang berbeza untuk mencapai pembelajaran maksimum.

Komponen mental yang dikaitkan dengan beban akademik diabaikan secara beransur-ansur membawa kepada tekanan dan kebimbangan yang pelajar tidak dapat untuk tangani. Oleh itu, beberapa penyelidik telah mencadangkan untuk mengkaji faktor kecerdasan emosi di pelbagai peringkat untuk memastikan kejayaan akademik pelajar terjamin. Selain itu dengan memahami impak hubungan kecerdasan emosi dan prestasi akademik pelajar akan membolehkan pendidik dan pengurus untuk memudahkan persekitaran pembelajaran mengikut ciri-ciri peribadi individu dan bukannya menggunakan penyelesaian yang sama untuk semua pelajar untuk mencapai hasil akademik yang terbaik (Khairatul Ulya, 2017). Di samping itu, pada masa yang sama mengkaji ciri-ciri kecerdasan emosi adalah penting bukan sahaja untuk meramalkan kejayaan akademik tetapi juga untuk memahami dan menjelaskan mekanisme yang memberikan impak terhadap prestasi pembelajaran pelajar (Nazri \& Salamuddin, 2019).

Banyak kajian terkini telah mendedahkan bahawa bukanlah hanya kecerdasan minda sahaja yang boleh dipercayai memberikan pengaruh terhadap pencapaian akademik pelajar (Qaiser Suleman et al., 2019). Salah satu sumber lain yang paling popular dan sering disebut adalah kecerdasan emosi melalui buku oleh Daniel Goleman yang popular bertajuk: Mengapa Ia Boleh Menjadi Lebih Daripada IQ (Eric Ng Chee Hong et al, 2016). Dalam bukunya Goleman (1995) telah mendakwa bahawa hanya $20 \%$ kejayaan seseorang individu boleh dikaitkan dengan kecerdasan minda dan di antara pelbagai faktor lain selain kecerdasan minda seperti kecerdasan emosi merupakan faktor penting dalam menentukan kejayaan individu sama ada dalam pendidikan atau dalam kerjaya mereka. Ini disokong oleh Qaiser et al. (2019) dan Prakas (2019) bahawa selain daripada keupayaan mental, emosi juga merupakan faktor dominan dalam menentukan kesejahteraan hidup individu. Oleh yang demikian, seseorang individu perlu belajar untuk mengawal emosi mereka dengan baik kerana ia merupakan salah satu faktor dalam menjayakan sesuatu urusan tidak kira urusan peribadi mahupun urusan profesional.

Negara kita mempunyai potensi untuk membangun menjadi sebuah negara maju seiring dengan negaranegara lain sekiranya rakyat berfikiran jauh, inovatif serta kreatif dan kritis. Oleh yang demikian, institusi pengajian tinggi tidak kira awam atau swasta berperanan untuk menghasilkan pelajar yang berkualiti supaya dapat memenuhi usaha untuk mentransformasikan negara ini (Nordin, 2017). Para pelajar siswazah atau pascasiswazah di institusi pengajian tinggi haruslah menyedari peranan mereka dan berusaha dalam mencapai kecemerlangan. Pencapaian akademik yang tinggi menjurus kepada kecerdasan mental yang tinggi dan ia merupakan aras penanda yang digunakan untuk mengukur tahap kecemerlangan akademik seseorang pelajar (Abdullah, Mesir \& Mohamad, 2019). Namun begitu, kecemerlangan akademik yang dihajati oleh pelajar adalah bukan disebabkan oleh faktor kecerdasan mental sahaja, kerana mungkin terdapat faktor lain yang boleh mempengaruhi kecemerlangan mereka seperti kecerdasan emosi (Rohaizah et al, 2018). Oleh yang demikian, kajian ini dilaksanakan untuk mengenal pasti hubungan yang wujud antara jenis-jenis kecerdasan emosi dengan prestasi akademik pelajar di institut pengajian tinggi dengan memberi fokus terhadap pelajar sarjana. 


\section{Sorotan Literatur}

Kecerdasan emosi adalah merupakan satu konsep yang moden dan nyata mempunyai kesan yang ketara terhadap kehidupan seseorang, dari segi cara berfikir, hubungan dan juga emosi. Interaksi antara perasaan dan fikiran adalah penting apabila membuat sesuatu keputusan atau membantu untuk berfikir dengan lebih jelas dan bijak (Manimozhi \& Srinivasan, 2019). Selain itu, tidak dapat dinafikan bahawa kecerdasan emosi pada masa kini merupakan salah satu topik perbahasan dan perbincangan yang popular terutamanya di dalam bidang sains sosial dan pendidikan. Terdapat banyak jurnal dan kajian telah dijalankan untuk mengkaji kecerdasan emosi sebagai fenomena multi-dimensi yang digunakan oleh penyelidikan teori dan aplikasi.

\section{Emosi}

Menurut Strongman (2018), emosi dikatakan berasal dari istilah Latin iaitu "emovere" yang bermaksud pengacau, pengaduk, atau penggerak untuk keluar. Beliau berpendapat bahawa emosi adalah perangsang yang menyebabkan seseorang individu melakukan sesuatu tindakan bagi memenuhi kepuasan diri. Beliau juga berpendapat bahawa individu yang mampu mengawal emosi mereka adalah individu yang cerdas serta mampu mengawal segala tindakan dalam kehidupan seharian. Manakala Habibah (2017) mendefinisikan kecerdasan emosi sebagai satu kebolehan untuk mempengaruhi serta mengawal emosi yang pelbagai, mendiskriminasikan emosi, serta menginterpretasikan emosi sebelum melaksanakan sesuatu tindakan. Berdasarkan pendapat tokoh-tokoh tersebut, dapat disimpulkan bahawa kecerdasan emosi memberi pengaruh terhadap tindakan yang akan dilakukan oleh seseorang individu.

\section{Prestasi Akademik}

Linggi, Jajat dan Kuston (2017), menyatakan bahawa prestasi akademik boleh didefinisikan sebagai perolehan hasil yang berupa ilmu pengetahuan, keterampilan, sikap dan nilai yang konsisten sehingga boleh menyumbang kepada perubahan seseorang individu sebagai hasil daripada pembelajaran. Hasil ini menjadi ukuran bagi mengenal pasti sejauh mana pelajar dapat menguasai dan memahami ilmu pelajaran yang dipelajari dan diajar semasa pembelajaran dan pengajaran. Rifiana (2015) berpendapat bahawa prestasi akademik pelajar adalah pencapaian yang menunjukkan tahap kecemerlangan akademik seseorang pelajar tersebut. Menurut beliau juga, prestasi akademik ini melambangkan potensi yang dicapai oleh pelajar iaitu tahap penguasaan pembelajaran dari segi kefahaman dan mampu mengaplikasikannya dalam kehidupan. Manakala Nazri dan Salamuddin (2019) pula menjelaskan bahawa prestasi akademik pelajar boleh diukur dengan melihat kepada nilai skor atau mata yang terkumpul melalui peperiksaan atau secara penilaian berterusan. Prestasi ini yakni dapat dilihat nilainya serta dapat ditentukan tahap kecemerlangannya.

\section{Pengaruh kecerdasan emosi}

Berdasarkan kajian Wirawan, Tamar dan Bellani (2020) mengenai pengaruh kecerdasan emosi terhadap pencapaian motivasi bagi kepimpinan guru besar di sekolah rendah, didapati bahawa kecerdasan emosi mempengaruhi pencapaian motivasi dari segi perlaksanaan tugas dan orientasi kepimpinan mereka. Berdasarkan kajian tersebut, kecerdasan emosi adalah berkolerasi dengan pencapaian motivasi yang ditunjukkan dengan hasil kajian bahawa emosi mempengaruhi motivasi pemimpin dalam melaksanakan sesuatu tanggungjawab. Selain itu, emosi juga memberi kesan terhadap orientasi kepimpinan individu yang menunjukkan bahawa individu dengan kecerdasan emosi yang tinggi menunjukkan tahap kepimpinan yang tinggi.

Kajian yang dilakukan di Sikkim, India oleh Rona dan Yugal (2017), mendapati bahawa majoriti iaitu sebanyak $72.95 \%$ pelajar didapati mempunyai tahap kecerdasan emosi yang normal, disusuli oleh $18.03 \%$ pelajar pula didapati menunjukkan tahap kecerdasan emosi yang rendah. Dapatan kajian tersebut juga mendapati $9.02 \%$ pelajar mempunyai kecerdasan emosi yang tinggi. Melalui kajian tersebut, hubungan positif wujud antara kecerdasan emosi seseorang pelajar dengan tahap pencapaian akademik mereka. Malahan mereka juga menyatakan bahawa kecerdasan emosi memberikan kesan 
mendalam bukan hanya kepada aspek akademik seseorang pelajar tetapi juga kejayaan mereka di masa hadapan.

Menurut kajian Rohaizad et al. (2018) pula, terdapat hubungan yang ketara antara prestasi akademik pelajar dengan kecerdasan emosi pelajar mereka. Tetapi, menurut dapatan kajian mereka, hubungan di antara keduanya adalah sangat lemah. Hasil kajian mereka sejajar dengan penemuan hasil kajian yang dijalankan oleh penyelidik lain yang mengatakan bahawa tiga daripada lima faktor utama kecerdasan emosi, seperti kesedaran diri, kawalan emosi dan empati memiliki hubungan ketara dengan kecemerlangan atau prestasi akademik seseorang pelajar. Antara lain mereka juga menyatakan bahawa antara domain yang memiliki kaitan adalah domain kawalan emosi, domain motivasi diri dan domain kepandaian diri.

Sementara itu, kajian yang telah dilakukan di Sabah oleh Mohd Nasir, Abdul Said dan Mohd Yusof (2018), yang bertajuk Pengaruh Kecerdasan Holistik Terhadap Kemenjadian Pelajar Tingkatan Enam di Sabah yang melibatkan seramai 418 pelajar juga menyimpulkan bahawa kecerdasan emosi adalah merupakan salah satu dimensi utama yang menjadi penyumbang dan pengaruh yang sangat tinggi terhadap kemenjadian seseorang pelajar. Analisis kajian mereka telah berjaya untuk membuktikan bahawa kecerdasan emosi adalah antara penentu yang baik bagi memastikan tahap kemenjadian seseorang individu dan khususnya pelajar yang menyertai kajian mereka.

Kebanyakan penyelidik mendapati bahawa kecerdasan emosi sememangnya mempunyai hubungan dan pengaruh terhadap tahap prestasi akademik seseorang individu baik di dalam bidang akademik mahupun kerjaya. Namun, dapatan kajian-kajian yang lepas juga menyatakan bahawa dalam kecerdasan emosi, terdapat banyak faktor yang boleh mempengaruhi kecerdasan emosi seseorang individu dan setiap faktor memberikan impak yang berbeza terhadap tahap peningkatan prestasi akademik seseorang pelajar.

\section{Teori Kecerdasan Emosi Goleman}

Goleman (1995) menganggap bahawa kecerdasan emosi sebagai suatu kompetensi yang boleh diperkembangkan melalui latihan. Beliau mengklasifikasikan kecerdasan emosi kepada beberapa domain yang utama iaitu kesedaran kendiri (self-awareness), pengurusan emosi kendiri (selfregulation), motivasi diri (motivation), empati (empathy) dan kemahiran sosial (social skills).

\section{i) Kesedaran kendiri}

Kesedaran kendiri bermaksud keupayaan seseorang dalam mengenali emosi dalam diri mereka. Keupayaan ini adalah merupakan kemampuan seseorang individu untuk memantau dan mengawasi perasaan mereka dari masa ke semasa. Faktor ini dapat menjadi pengaruh terhadap kepekaan seseorang apabila membuat sesuatu keputusan dalam masalah peribadi mereka.

\section{ii) Menguruskan emosi}

Komponen pengurusan emosi kendiri adalah merupakan kebolehan seseorang dalam mengurus, menangani, dan mengawasi emosi mereka. Contohnya kebolehan untuk menghiburkan diri mereka sendiri, mengawal kegelisahan, tekanan, kemurungan dan perasaan lain yang muncul dalam diri mereka. Individu yang dapat mengawal emosi mereka dengan baik dikatakan mampu untuk menghadapi dan menangani cabaran, dugaan, kesusahan yang mereka alami sehingga mampu untuk bangun kembali dari situasi negatif itu. Manakala, seseorang yang tidak pandai untuk mengawal dan mengatur emosi mereka pula akan melakukan sebaliknya dan akan terus berada dalam situasi yang negatif dan tidak sihat.

\section{iii) Motivasi}

Individu yang berupaya untuk memotivasikan diri mereka sendiri akan lebih produktif dan efektif dalam semua kegiatan dan perbuatan yang mereka lakukan. Kemampuan seseorang untuk memberikan motivasi kepada diri mereka sendiri antaranya termasuklah optimis, mahir dalam pemikiran positif, dan mempunyai kawalan desakan hati mereka. 
iv) Empati

Individu yang menyandang sikap empati dalam diri mereka dapat membaca, menyedari, dan memahami pandangan orang lain. Mereka mampu untuk menyesuaikan diri mereka dengan orang lain dan dapat membina hubungan dan kepercayaan di antara mereka. Dinyatakan bahawa, individu yang mempunyai empati dalam diri mereka lebih mudah bergaul dan bersosial kerana mereka dapat membaca apa yang diperlukan oleh individu yang lain.

v) Hubungan sosial

Individu yang mempunyai kemampuan untuk membina dan menjalinkan hubungan dengan individu yang lain dengan lebih baik dapat membaca, memahami dan lebih peka dalam menganalisis reaksi yang dipamerkan dan ini akan membantu mereka untuk menangani sebarang masalah atau konflik yang muncul. Individu yang mempunyai ciri ini juga dikatakan mampu untuk menjadi pemimpin bagi sesebuah organisasi.

Komponen-komponen yang telah dinyatakan di atas membuktikan bahawa sekiranya seseorang individu mempunyai kecerdasan emosi yang tinggi, maka mereka mempunyai kebolehan dan sikap yang lebih optimis apabila menghadapi konflik, memiliki kebolehan untuk memotivasikan diri mereka sendiri, dapat mengawal kehendak hati mereka, berkemampuan untuk mengenali dan menangani emosi dengan bijak, mempunyai empati terhadap orang lain dan akhirnya dapat mewujudkan hubungan yang positif dengan individu dalam sesebuah komuniti.

\section{Metod Kajian}

\section{Reka bentuk kajian, populasi dan sampel}

Reka bentuk kajian yang dipilih menjadi rujukan utama kepada pengkaji untuk merangka sesuatu kajian. Menurut Farnsworth (2019), penyelidikan kuantitatif ini dapat digunakan untuk memudahkan penyelidik mengukur pendapat, sikap, perilaku seseorang individu dan juga hubungan pemboleh ubah yang telah ditentukan oleh pengkaji bagi sesuatu kajian dengan matlamat untuk melihat sekiranya terdapat hubungan atau tidak mengenai sesuatu topik kajian tertentu dan ia juga sesuai untuk digunakan bagi jumlah populasi kajian yang lebih banyak Kajian ini dilaksanakan dengan menggunakan kaedah kuantitatif secara tinjauan (survey) berasaskan soal selidik. Menurut Adi Bhat (2020), kaedah penyelidikan yang menggunakan tinjauan bagi tujuan untuk mengumpulkan data daripada satu kumpulan responden yang telah dikenal pasti bagi membolehkan pengkaji untuk mengumpulkan maklumat serta maklum balas mengenai berbagai topik yang menarik.

Populasi kajian ini adalah pelajar pascasiswazah di sebuah universiti awam di Bangi. Kaedah bagi persampelan yang dipilih dalam kajian ini adalah persampelan jenis rawak mudah. Berdasarkan Chua (2017), penggunaan jenis persampelan ini membolehkan setiap unsur di dalam sesebuah populasi tersebut mempunyai kebarangkalian yang sama untuk dipilih. Sampel diambil dalam kalangan pelajar sarjana semester dua dan ke atas yang sedang menduduki pengajian di universiti tersebut. Seramai 121 orang pelajar terlibat dalam menjawab soal selidik yang diedarkan.

\section{Instrumen kajian}

Kajian ini menggunakan instrumen soal selidik yang telah diadaptasi dari Inventori Kecerdasan Emosi yang dibangunkan oleh Goleman (1995). Instrumen Inventori Kecerdesan Emosi ini adalah berdasarkan lima dimensi kecerdasan emosi yang akan dikaji iaitu kesedaran diri, menguruskan emosi, motivasi diri, empati dan kemahiran sosial. Setiap dimensi yang dinyatakan mempunyai sepuluh soalan sebagai subkonstruk. Pembahagian soal selidik terdiri daripada dua bahagian iaitu A dan B. Pada bahagian A merangkumi berkenaan latar belakang seperti jantina, umur dan prestasi akademik responden iaitu pelajar sarjana. Prestasi akademik responden adalah berdasarkan Purata Nilai Gred Kumulatif atau lebih dikenali sebagai CGPA (Cumulative Grade Point Average) yang telah diperoleh oleh responden. 
Manakala, soalan-soalan dalam Bahagian B bertujuan untuk melihat dimensi-dimensi kecerdasan emosi responden. Soal-selidik ini menggunakan format Skala Likert iaitu skala bernombor yang ditetapkan oleh pengkaji. Menurut Appelbaum et al. (2018), likert skala lima dipilih kerana senang diuruskan dan diguna pakai, item-itemnya dapat dijawab oleh responden dengan mudah, data yang dikutip melalui skala ini menunjukkan kepercayaan yang lebih tinggi berbanding dengan skala lain seperti Guttman (1950) yang hanya menunjukkan dua jawapan sahaja iaitu 'ya' dan 'tidak'. Kajian yang menggunakan kaedah soal selidik adalah lebih cekap dalam pengumpulan data sekiranya penyelidik bagi sesuatu kajian tahu akan pemboleh ubah yang boleh diukur dengan tepat dan tahu apakah jawapan yang diharapkan daripada kumpulan responden yang telah dipilih (Shuhairy et al., 2018).

Jadual 1: Skor dan persetujuan terhadap Pernyataan Item Bahagian B

\begin{tabular}{lc}
\hline Jawapan & Skor \\
\hline Sangat tidak setuju & 1 \\
Tidak setuju & 2 \\
Tidak pasti & 3 \\
Setuju & 4 \\
Sangat setuju & 5 \\
\hline
\end{tabular}

\section{Kajian rintis}

Kajian rintis dilaksanakan terhadap 30 orang pelajar sebelum kajian sebenar dilakukan bagi menentukan kebolehpercayaan item-item soal selidik. Nilai kebolehpercayaan Cronbach's alpha bagi item-item soal selidik secara keseluruhan bagi kajian ini adalah pada nilai 0.757. Menurut Liu (2019), pekali alpha yang kurang daripada 0.6 adalah lemah manakala pada julat 0.7-0.8 adalah pada tahap yang baik. Berdasarkan nilai tersebut, ini menunjukkan bahawa item-item soal selidik bagi kajian mempunyai kebolehpercayaan pada tahap yang baik

\section{Kaedah penganalisisan data}

Analisis statistik iaitu deskriptif dan inferensi digunakan untuk menganalisis data bagi kajian ini. Melalui analisis deskriptif, peratusan, min dan sisihan piawai digunakan untuk mengenal pasti taburan dimensi kecerdasan emosi. Manakala analisis korelasi Pearson, iaitu analisis inferensi digunakan untuk menunjukkan hubungan antara pemboleh ubah kecerdasan emosi dengan pencapaian akademik pelajar sarjana.

\section{Hasil kajian}

Tujuan bagi kajian ini adalah bagi mengenal pasti hubungan antara kecerdasan emosi dengan prestasi akademik dalam kalangan pelajar sarjana. Terdapat lima komponen utama bagi kecerdasan emosi dalam kajian ini iaitu kesedaran diri, menguruskan emosi, motivasi diri, empati dan kemahiran sosial.

Jadual 2 merupakan taburan bagi komponen kecerdasan emosi iaitu kesedaran diri. Hasil dapatan juga menunjukkan pelbagai tanggapan responden terhadap kesedaran diri. Bagi skor min menunjukkan bahawa "Saya tahu bila saya gembira dengan prestasi akademik saya" mencatatkan min yang tertinggi ( $\mathrm{Min}=4.69, \mathrm{SP}=0.514)$ dan "Saya dapat melepaskan kemarahan dengan cepat sehingga tidak lagi mempengaruhi saya" mencatatkan min yang terendah ( $\mathrm{Min}=3.36, \mathrm{SP}=1.154)$. Berdasarkan analisis secara deskriptif ini, secara keseluruhannya responden bersetuju terhadap kesedaran diri apabila nilai min adalah 4.169 dan sisihan piawai adalah 0.454 . 


\section{Jadual 2: Kesedaran Diri}

\begin{tabular}{|c|c|c|}
\hline Pernyataan & Min & SP \\
\hline Saya sedar dengan cepat apabila saya hilang sabar & 4.24 & 0.764 \\
\hline Saya tahu bila saya gembira dengan prestasi akademik saya & 4.69 & 0.514 \\
\hline Saya biasanya mengetahui apabila saya tertekan & 4.31 & 0.825 \\
\hline Apabila saya 'emosional', saya sedar akan perkara ini & 4.3 & 0.726 \\
\hline Apabila saya merasa cemas, saya kebiasaannya dapat menjelaskan alasan saya & 3.76 & 0.958 \\
\hline Saya selalu tahu bila saya tidak masuk akal & 3.85 & 0.972 \\
\hline Kesedaran tentang emosi saya sendiri sangat penting bagi saya setiap masa & 4.53 & 0.578 \\
\hline $\begin{array}{l}\text { Saya dapat mengetahui sama ada seseorang telah mengganggu emosi saya atau } \\
\text { membuatkan saya marah }\end{array}$ & 4.21 & 0.744 \\
\hline $\begin{array}{l}\text { Saya dapat melepaskan kemarahan dengan cepat sehingga tidak lagi } \\
\text { mempengaruhi saya }\end{array}$ & 3.36 & 1.154 \\
\hline Saya tahu apa yang menggembirakan saya & 4.45 & 0.774 \\
\hline Keseluruhan & 4.169 & 0.454 \\
\hline
\end{tabular}

Bagi komponen kedua dalam aspek kecerdasan emosi ialah menguruskan emosi. Jadual 3 menunjukkan dapatan kajian bagi komponen tersebut. Hasil dapatan juga menunjukkan pelbagai tanggapan responden terhadap pengurusan emosi. Bagi skor min menunjukkan bahawa "Orang lain sering tidak tahu bagaimana perasaan saya tentang sesuatu perkara" mencatatkan min yang tertinggi (Min=3.89, $\mathrm{SP}=1.015)$ dan "Saya jarang bimbang tentang prestasi dan pencapaian akademik saya" mencatatkan min yang terendah $(\mathrm{Min}=2.6, \mathrm{SP}=1.435)$. Berpandukan kepada dapatan deskriptif ini, secara keseluruhannya responden neutral terhadap menguruskan emosi apabila nilai min adalah 3.503 dan sisihan piawai adalah 0.574 .

Jadual 3: Menguruskan Emosi

\begin{tabular}{lcc}
\hline \multicolumn{1}{c}{ Pernyataan } & Min & SP \\
\hline Saya dapat 'membetulkan semula' perasaan buruk dengan cepat & 3.18 & 1.176 \\
Saya tidak menunjukkan perasaan saya dengan ketara & 3.6 & 1.107 \\
Orang lain jarang untuk mengetahui perasaan yang saya rasai & 3.74 & 1.053 \\
Saya jarang marah terhadap orang lain & 3.52 & 1.126 \\
Orang yang sukar tidak menjengkelkan saya & 3.11 & 1.23 \\
Saya dapat secara sedar mengubah fikiran atau mood saya & 3.73 & 0.806 \\
Saya tidak membiarkan keadaan tertekan atau orang mempengaruhi & & \\
pembelajaran saya & 3.84 & 0.992 \\
Saya jarang bimbang tentang prestasi dan pencapaian akademik saya & 2.6 & 1.435 \\
Saya dapat menenangkan emosi saya apabila saya perlu & 3.82 & 0.992 \\
Orang lain sering tidak tahu bagaimana perasaan saya tentang sesuatu perkara & 3.89 & 1.015 \\
$\quad$ Keseluruhan & $\mathbf{3 . 5 0 3}$ & $\mathbf{0 . 5 7 4}$ \\
\hline
\end{tabular}

Seterusnya, motivasi diri merupakan komponen ketiga dalam kecerdasan emosi. Dapatan kajian dinyatakan dengan jelas dalam Jadual 4. Hasil dapatan juga menunjukkan pelbagai tanggapan responden terhadap motivasi diri. Bagi skor min menunjukkan bahawa "Rasa berterima kasih adalah pegangan prinsip saya" mencatatkan min yang tertinggi (Min=4.41, $\mathrm{SP}=0.771$ ) dan "Saya tidak pernah membuang masa" mencatatkan min yang terendah (Min=2.97, $\mathrm{SP}=1.245$ ). Berpandukan kepada dapatan deskriptif ini, secara keseluruhannya responden neutral terhadap motivasi diri apabila nilai min adalah 3.861 dan sisihan piawai adalah 0.543 .

Jadual 4: Motivasi Diri

\begin{tabular}{lcc}
\hline \multicolumn{1}{c}{ Pernyataan } & Min & SP \\
\hline Saya dapat memotivasikan diri sendiri bagi melakukan tugas yang sukar & 4 & 0.816 \\
Saya biasanya dapat mengutamakan aktiviti penting bagi pembelajaran dan & 4.07 & 0.838
\end{tabular}


meneruskannya

Saya selalu memenuhi tarikh penghantaran tugasan saya

Saya tidak pernah membuang masa

Saya tidak akan mengelirukan orang

Saya percaya anda harus melakukan perkara yang sukar terlebih dahulu

Rasa berterima kasih adalah pegangan prinsip saya

Saya sentiasa dapat memotivasikan diri saya walaupun saya merasa rendah diri

Komponen keempat dalam kecerdasan emosi adalah empati di mana dapatannya dinyatakan dalam Jadual 5. Hasil dapatan juga menunjukkan pelbagai tanggapan responden terhadap empati. Bagi skor min menunjukkan bahawa "Saya dapat merasakan sekiranya seseorang tidak selesa dan senang dengan saya" mencatatkan min yang tertinggi (Min=4.17, $\mathrm{SP}=0.771)$ dan "Saya mahir apabila perlu berhadapan dengan masalah orang lain" mencatatkan min yang terendah ( $\mathrm{Min}=3.69, \mathrm{SP}=0.913$ ). Berpandukan kepada dapatan deskriptif ini, secara keseluruhannya responden neutral terhadap empati apabila nilai min adalah 3.952 dan sisihan piawai adalah 0.476 .

Jadual 5: Empati

\begin{tabular}{lcc}
\hline \multicolumn{1}{c}{ Pernyataan } & Min & SP \\
\hline Saya kebiasaannya dapat melihat daripada sudut pandangan orang lain & 3.96 & 0.831 \\
Saya mahir apabila perlu berhadapan dengan masalah orang lain & 3.69 & 0.913 \\
Saya dapat merasakan sekiranya seseorang tidak selesa dan senang dengan & 4.17 & 0.771 \\
saya & & \\
Saya dapat mengetahui sekiranya sekumpulan orang tidak mempunyai & 4.12 & 0.714 \\
keharmonian sesama sendiri & 3.72 & 1.051 \\
Saya biasanya dapat memahami mengapa orang menjadi sukar terhadap saya & 4.12 & 0.798 \\
Individu lain tidak sukar hanya berbeza & 3.84 & 0.856 \\
Saya dapat memahami sekiranya saya tidak masuk akal & 3.93 & 0.873 \\
Saya dapat memahami mengapa tindakan saya kadang-kadang menyinggung & 4.09 & 0.796 \\
perasaan orang lain & 3.88 & 0.924 \\
Saya kadang-kadang dapat melihat sesuatu dari sudut pandangan orang lain & $\mathbf{3 . 9 5 2}$ & $\mathbf{0 . 4 7 6}$ \\
\hline Sebab tidak setuju selalu jelas bagi saya & &
\end{tabular}

Kemahiran sosial dikategorikan sebagai komponen yang terkandung dalam kecerdasan emosi. Jadual 6 merupakan taburan bagi kemahiran sosial. Hasil dapatan juga menunjukkan pelbagai tanggapan responden terhadap kemahiran sosial. Bagi skor min menunjukkan bahawa "Saya seorang pendengar yang baik" mencatatkan min yang tertinggi (Min=4.26, $\mathrm{SP}=0.772$ ) dan "Saya suka bertemu dengan orang baru dan mengenali apa yang membuatkan mereka marah" mencatatkan min yang terendah (Min=3.43, SP=1.139). Berpandukan kepada dapatan deskriptif ini, secara keseluruhannya responden neutral terhadap kemahiran sosial apabila nilai min adalah 3.848 dan sisihan piawai adalah 0.586 .

Jadual 6: Kemahiran Sosial

\begin{tabular}{lcc}
\hline \multicolumn{1}{c}{ Pernyataan } & Min & SP \\
\hline Saya seorang pendengar yang sangat baik & 4.26 & 0.772 \\
Saya tidak akan pernah mengganggu perbualan orang lain & 3.89 & 0.964 \\
$\begin{array}{l}\text { Saya pandai menyesuaikan diri dan bergaul dengan pelbagai orang } \\
\text { Bersosial adalah perkara paling menarik dalam hidup saya }\end{array}$ & 3.93 & 0.914 \\
$\begin{array}{l}\text { Saya suka bertemu dengan orang baru dan mengenali apa yang } \\
\text { membuatkan mereka marah }\end{array}$ & 3.62 & 1.105 \\
$\begin{array}{l}\text { Saya memerlukan pelbagai rakan belajar untuk membuat pembelajaran } \\
\text { saya menarik }\end{array}$ & 3.43 & 1.139 \\
$\quad$ www.msocialsciences.com & & 1.025
\end{tabular}


Saya suka bertanyakan soalan untuk mengetahui apa yang penting bagi orang lain

Saya melihat belajar dengan orang yang sukar sebagai satu cabaran untuk memenangi mereka

Saya pandai mendamaikan masalah dan perselisihan dengan orang lain Saya secara amnya membina hubungan yang erat dengan rakan belajar yang lain

Keseluruhan

Hubungan antara jenis-jenis kecerdasan emosi dengan prestasi akademik pelajar sarjana dinyatakan dalam Jadual 7. Bagi nilai pekali korelasi, $r$ bagi faktor kesedaran diri adalah bersamaan dengan 0.208*, menguruskan emosi adalah $0.457^{*}$, motivasi diri adalah $0.319^{*}$, empati adalah $0.202^{*}$ dan kemahiran sosial adalah $0.532^{*}$. Ini menunjukkan korelasi yang lemah bagi semua pemboleh ubah (kesedaran diri, menguruskan emosi, motivasi diri dan empati) kecuali kemahiran sosial mempunyai korelasi yang sederhana. Berdasarkan nilai $\mathrm{p}=0.029,0.017,0.003,0.026$ dan 0.000 bagi semua pemboleh ubah menunjukkan nilai lebih kecil daripada 0.05 maka hipotesis nul ditolak. Daripada data tersebut jelaslah bahawa terdapat hubungan yang signifikan antara prestasi akademik pelajar sarjana iaitu gred CGPA dan komponen-komponen bagi kecerdasan emosi iaitu kesedaran diri, menguruskan emosi, motivasi diri, empati dan kemahiran sosial. Oleh sebab keputusan ujian menunjukkan terdapat hubungan yang signifikan, maka dengan ini dapat dirumuskan bahawa hubungan kolerasi wujud antara dimensi kecerdasan emosi dengan prestasi akademik pelajar sarjana.

Jadual 7: Hubungan Kecerdasan Emosi dengan Pencapaian Akademik Pelajar Sarjana

\begin{tabular}{llccccc}
\hline & $\begin{array}{c}\text { Kesedaran } \\
\text { Diri }\end{array}$ & $\begin{array}{c}\text { Menguruskan } \\
\text { Emosi }\end{array}$ & $\begin{array}{c}\text { Motivasi } \\
\text { Diri }\end{array}$ & Empati & $\begin{array}{c}\text { Kemahiran } \\
\text { Sosial }\end{array}$ \\
\hline $\begin{array}{l}\text { Prestasi } \\
\text { Akademik }\end{array}$ & $\begin{array}{l}\text { Pearson } \\
\text { Correlation }\end{array}$ & $0.208^{*}$ & $0.457^{*}$ & $0.319^{*}$ & $0.202^{*}$ & $0.532^{*}$ \\
& $\begin{array}{l}\text { Sig. (2- } \\
\text { tailed) }\end{array}$ & 0.029 & 0.017 & 0.003 & 0.026 & 0.000 \\
& $\mathrm{~N}$ & 121 & 121 & 121 & 121 & 121 \\
\hline
\end{tabular}

Aras keertian $\alpha=0.05$

Jadual 8 menunjukkan nilai pekali korelasi, $r$ bagi faktor prestasi akademik dengan kecerdasan emosi secara keseluruhan berdasarkan komponen-komponen kecerdasan yang dikaji adalah bersamaan dengan 0.161*. Ini menunjukkan korelasi positif iaitu pemboleh ubah adalah saling berkadar terus. Memandangkan nilai $\mathrm{p}=0.02$ adalah lebih kecil daripada 0.05 maka hipotesis nul ditolak. Hasil data menunjukkan hubungan yang signifikan antara kecerdasan emosi dan prestasi akademik pelajar sarjana. Oleh kerana keputusan ujian korelasi menunjukkan terdapat hubungan yang signifikan, maka dengan ini dapat dirumuskan bahawa terdapat hubungan yang signifikan antara kecerdasan emosi dan prestasi akademik bagi kajian ini.

Jadual 8: Nilai Kolerasi Kecerdasan Emosi dan Pencapaian Akademik Pelajar Sarjana

\begin{tabular}{llcc}
\hline & & $\begin{array}{c}\text { Kecerdasan } \\
\text { Emosi }\end{array}$ & $\begin{array}{c}\text { Pencapaian } \\
\text { Akademik }\end{array}$ \\
\hline Kecerdasan & Pearson Correlation & 1 & $0.161^{*}$ \\
Emosi & Sig. (2-tailed) & & 0.020 \\
& $\mathrm{~N}$ & 121 & 121 \\
\hline
\end{tabular}

Aras keertian $\alpha=0.05$ 


\section{Perbincangan Kajian}

\section{Hubungan antara jenis-jenis kecerdasan emosi dengan pencapaian akademik pelajar sarjana}

Kajian ini memfokuskan pelbagai jenis kecerdasan emosi yang dimiliki oleh pelajar sarjana seperti kesedaran diri, pengurusan emosi, motivasi diri, empati dan kemahiran sosial. Berdasarkan dapatan kajian, jelas menunjukkan kesedaran diri merupakan jenis kecerdasan emosi yang paling dominan. Menurut aspek kesedaran diri, nilai min yang tertinggi menunjukkan bahawa responden mengetahui apabila dia gembira dengan pencapaian akademiknya. Dapatan kajian ini seiring dengan kajian yang dijalankan oleh Muhamad et al. (2020) bahawa kesedaran diri merupakan satu dimensi dalam menentukan kecerdasan emosi. Turut disokong oleh Goleman (1995) di mana kesedaran diri merupakan elemen yang menyumbang kepada kecerdasan emosi dan ianya mempengaruhi pencapaian akademik dalam kalangan pelajar.

Dari sudut pengurusan emosi, dapatan kajian menunjukkan bahawa responden menyatakan orang lain sering tidak tahu bagaimana perasaannya terhadap sesuatu. Di sini jelas menunjukkan bahawa responden menguruskan emosinya secara kendiri dengan baik agar tidak memberi impak negatif terhadap prestasi akademiknya. Dapatan kajian ini turut disokong oleh Ahmad dan Ambotang (2020) bahawa kecerdasan emosi memberi pengaruh terhadap prestasi akademik pelajar. Situasi yang jelas dapat dilihat apabila pengurusan emosi yang sistematik dalam memastikan tahap kecerdasan emosi yang baik dalam kalangan pelajar di sekitar Tawau, Sabah. Di sini dapat disimpulkan bahawa emosi menjadi indikator kepada prestasi akademik individu. Tambahan pula, Che Ani (2013) turut melaporkan bahawa pengurusan emosi memberi impak terhadap pencapaian akademik di mana ianya dibuktikan menerusi pencapaian akademik dalam kalangan pelajar Diploma Pendidikan Lepasan Ijazah (DPLI) Universiti Tun Hussein Onn Malaysia. Hasil kajian melaporkan bahawa emosi para pelajar memberi pengaruh terhadap pencapaian akademik mereka.

Dalam konteks motivasi diri, responden sentiasa menjadikan motivasi sebagai kunci kejayaannya agar dapat menonjolkan keupayaan diri sehingga ke tahap paling optimum. Dengan adanya motivasi diri yang tinggi, ianya mendorong kecerdasan emosi dan sosial yang optimum dan secara tidak langsung membolehkan individu mencapai kecemerlangan diri yang optimum. Ini disokong Sulaiman et al. (2018) dalam kajian beliau terhadap subjek Pendidikan Agama Islam di mana motivasi diri mendorong kecerdasan emosi pelajar dalam menguasai sesuatu mata pelajaran. Dapatan yang sama turut dilaporkan oleh Rifiana (2015) bahawa motivasi diri secara intrinsik dan ekstrinsik memberi kesan terhadap pencapaian akademik dalam kalangan pelajar.

Pencapaian akademik yang bagus sudah semestinya mempunyai pengaruh dari atribusi atau domain kecerdasan emosi seperti empati. Di sini jelas menunjukkan bahawa empati adalah salah satu elemen kecerdasan emosi yang mampu mempengaruhi kejayaan individu. Ianya turut disokong oleh Amalia dan Slamet (2019) dalam kajian yang dijalankan bahawa kecerdasan emosi dan spiritual memberi impak terhadap kepimpinan dan pencapaian pelajar yang memberi fokus terhadap domain empati. Seorang pelajar bukan sahaja perlu mempunyai sifat simpati terhadap orang lain dalam diri mereka namun mereka juga perlu belajar untuk memahami perasaan individu di sekeliling diri mereka. Sekiranya pelajar dapat memupuk perasaan ini dalam diri mereka, nescaya ia akan mendorong mereka untuk menjadi individu yang berjaya tidak kira dalam pekerjaan ataupun pembelajaran. Menurut kajian yang dijalankan oleh Yahaya et al. (2010), kecerdasan emosi dalam konteks empati mempunyai hubungan yang signifikan dengan pencapaian akademik pelajar. Hasil kajian beliau menunjukkan bahawa individu yang lebih berempati terhadap individu di sekeliling lebih mudah didekati dan secara tidak langsung mempunyai emosi yang stabil serta mampu fokus dalam pembelajaran. Secara tidak langsung, ianya menjelaskan bahawa aspek empati harus diberikan fokus agar tidak menjejaskan prestasi akademik pelajar.

Menurut aspek kemahiran sosial dengan nilai kolerasi yang paling tinggi, responden menyatakan bahawa pendengar yang baik merupakan kemahiran sosial yang perlu dikuasai agar dapat memberi impak yang positif kepada emosi dan seterusnya mendorong peningkatan dalam prestasi akademik. 
Seperti yang dinyatakan oleh Ying (2017), kecerdasan emosi mempunyai perkaitan dengan kecerdasan sosial di mana ianya adalah salah satu domain yang mempunyai pengaruh terhadap kecerdasan emosi kerana ia membolehkan seseorang faham akan perasaan dan emosi dirinya serta individu lain. Secara tidak langsung, ianya mendorong pencapaian yang cemerlang. Dengan merujuk kepada kajian yang dijalankan terhadap pelajar Sarjana Muda Psikologi di Kolej Universiti Islam Melaka (KUIM), pencapaian akademik mereka turut dipengaruhi oleh kecerdasan emosi di mana secara spesifiknya adalah disebabkan oleh kemahiran sosial (Razali \& Raop, 2019).

Berdasarkan dapatan kajian yang dilaporkan, jelas menunjukkan bahawa kesedaran emosi mempengaruhi prestasi akademik pelajar. Ianya turut disokong oleh Nazri dan Salamuddin (2019) bahawa kecerdasan emosi memberi impak terhadap pencapaian akademik pelajar. Hal ini ditekankan Goleman (1995) bahawa tahap kecerdasan emosi seseorang individu adalah merupakan faktor penentu kejayaan individu tersebut. Hal ini jelas bahawa pengurusan emosi secara terkawal merupakan elemen penting yang diberi perhatian dalam kehidupan seseorang individu yang ingin mencapai kejayaan (Abi, 2019).

\section{Limitasi dan Cadangan Kajian Lanjutan}

Dapatan kajian ini dapat dijadikan sumber kajian kepada pengkaji bagi mengenal pasti jenis-jenis kecerdasan emosi dan kesannya terhadap prestasi akademik pelajar. Di samping itu juga, ianya turut membuka ruang kepada pensyarah serta pakar psikologi untuk memahami setiap jenis kecerdasan emosi dan impaknya terhadap prestasi akademik pelajar. Beberapa cadangan kajian perlu dipertimbangkan untuk kajian seterusnya. Antaranya ialah tumpuan kajian kepada pelajar sekolah juga di mana mereka turut berhadapan dengan pelbagai bentuk emosi di mana ianya turut mempengaruhi prestasi akademik yang ditonjolkan. Di samping itu juga, penglibatan ibu bapa turut ditekankan dalam membantu pelajar untuk mengawal emosi mereka agar tidak memberi pengaruh negatif terhadap prestasi akademik. Selain itu, kajian boleh juga dibesarkan skopnya kepada pelajar sekolah dan pelajar universiti bagi menilai impak kecerdasan emosi terhadap prestasi akademik. Tambahan pula, turut dicadangkan untuk mengkaji corak dan gaya pengajaran pensyarah dalam meningkatkan kesediaan pelajar bagi meningkatkan prestasi akademik mereka.

Kecerdasan emosi dilihat menjadi satu aspek yang penting bagi mendorong peningkatan dalam prestasi akademik pelajar. Berikutan itu, kajian ini mendorong ibu bapa, tenaga pengajar serta pihak universiti untuk mengambil berat tentang emosi pelajar sarjana terutamanya yang difokuskan dalam kajian ini. Cadangan tersebut turut dinyatakan oleh Mensih et al. (2021) dalam kajiannya untuk mengkaji hubungan antara motivasi pencapaian kecerdasan emosi dan ketahanan diri dalam kalangan mahasiswa kerja sosial. Tambahan pula, dalam usaha meningkatkan prestasi akademik dalam kalangan pelajar, sebagai tenaga pengajar iaitu pensyarah perlu meningkatkan tahap keupayaan mereka dalam memastikan pemahaman pelajar berada pada tahap optimum dengan menghadiri kursus pembangunan kendiri. Selain itu, aspek kemanusiaan juga perlu ditingkatkan agar dapat meningkatkan tahap kecerdasan emosi dalam kalangan pelajar. Ianya turut disokong oleh Talib et al. (2017) dalam kajiannya bagi mengenal pasti kecerdasan emosi dan sikap pembelajaran pelajar terhadap pencapaian kursus Tamadun Islam. Sebagai contoh, tenaga pengajar perlu menunjukkan tingkah laku yang positif seperti kepimpinan serta sikap mengambil berat bagi mewujudkan suasana pembelajaran yang berkesan kepada pelajar. Berikutan itu, tenaga pengajar juga haruslah menyiapkan diri dengan pelbagai ilmu pengetahuan dan tidak terhad kepada teori-teori di dalam sahaja kerana mereka akan menjadi panduan yang efektif dalam hidup pelajar.

\section{Kesimpulan}

Melihat betapa besarnya peranan kecerdasan emosi seperti yang diketengahkan dalam kajian ini, ianya memberi impak yang positif terhadap perasaan, dan seterusnya prestasi akademik pelajar sarjana. Pemupukan terhadap kecerdasan emosi pelajar haruslah diberi penekanan seiring dengan kecerdasan mental pelajar. Pendidik berperanan mengamalkan sikap menyokong dan memberi galakan serta 
dorongan tanpa mengira perbezaan status ekonomi sosial para pelajar. Sekiranya kecerdasan emosi diberi penekanan, jelaslah bahawa suasana pembelajaran yang efektif dapat diwujudkan seterusnya dapat menghasilkan modal insan yang seimbang dari segi jasmani, emosi, rohani dan intelek.

\section{Rujukan}

Abdullah, A., Mesir, B. \& Mohamad, A.M. (2019). Faktor-Faktor Yang Menyumbang Kepada Kecemerlangan Akademik Pelajar di Universiti Teknologi Malaysia. Jurnal Teknologi (Sciences and Engineering).

Abi, A. R. (2019). Kecerdasan Emosional Dalam Kepemimpinan Pendidikan. SOTIRIA Jurnal Theologia dan Pendidikan Agama Kristen, 2(1), 60-68.

Adi Bhat. (2020). Qualitative Research: Definition, Types, Methods and Examples. Dimuat turun pada 5 April 2021 dari laman web https://www.thoughtco.com/qualitative-research-methods3026555.

Ahmad, A. A., \& Ambotang, A. S. B. (2020). Pengaruh kecerdasan emosi, kecerdasan spiritual dan persekitaran keluarga terhadap stres akademik murid sekolah menengah. Malaysian Journal of Social Sciences and Humanities (MJSSH), 5(5), 12-23.

Amalia, D., \& Slamet, M. R. (2019). Pengaruh Kecerdasan Emosional dan Kecerdasan Spiritual terhadap Kepemimpinan Transformasional Dilihat dari Perspektif Gender. Journal of Applied Managerial Accounting, 3(1), 126-139.

Appelbaum, M., Cooper, H., Kline, R. B., Mayo-Wilson, E., Nezu, A. M., \& Rao, S. M. (2018). Journal article reporting standards for quantitative research in psychology: The APA Publications and Communications Board task force report. American Psychologist, 73(1), 3.

Che Ani, R. (2013). Kecerdasan emosi dalam kalangan Pelajar Diploma Pendidikan Lepasan Ijazah (DPLI) Universiti Tun Hussein Onn Malaysia (Doctoral dissertation, Universiti Tun Hussein Onn Malaysia).

Chua Yan Piaw. (2017). Do computer-mediated communication skill, knowledge and motivation mediate the relationships between personality traits and attitude toward Facebook? Computers in Human Behavior 70, 51-59.

Eric Ng Chee Hong, Lam Zheng Hao, Ramesh Kumar, Charles Ramendran \& Vimala Kadiresan. (2016). The Effectiveness of Human Resource Management Practices on Employee Retention in Institute of Higher learning: A regression analysis. International Journal of Business Research and Management (IJBRM), 3.

Fakhar, A., Shakoor, F., \& Abbas, J. (2021). Impact of Smartphones Usage on the Learning Behaviour and Academic Performance of Students: Empirical Evidence from Pakistan. International Journal of Academic Research in Business and Social Sciences, 11(2), 862-881.

Fransworth, J. (2019). Is and Ought: Descriptive and Prescriptive Cognitions in Military-Related Moral Injury. Journal of Traumatic Stress, 32(3).

Goleman, D. (1995). Emotional intelligence. New York: Bantam Books.

Goleman, D. (2018). Emotional Intelligence: Why It Can Matter More Than IQ $25^{\text {th }}$ Edition. New York: Bantam Books.

Guttman, L. (1950). "The basis for scalogram analysis" In E. A. Stouffer, Measurement and Prediction. Wiley, New York.

Habibah@Artini Ramlie. (2017) Pembangunan model profesionalisme guru Pendidikan Islam berasaskan 'Riadhah Ruhiyyah'. PhD thesis, University of Malaya.

Khairatul Ulya. (2017). Korelasi Kecerdasan Emosi Dan Indeks Prestasi Akademik Mahasiswa. Program Studi Pendidikan Matematika, Fakultas Tarbiyah dan Keguruan, Universitas Islam Negeri Ar Raniry.

Linggi, A., \& Jajat, J., \& Kuston, S. (2017). Hubungan Kecerdasan Emosi dengan Prestasi Akademik Mahasiswa Olahraga. Jurnal Terapan Ilmu Keolahragaan.

Liu, K. (2019). Effects of sample size, dry ashing temperature and duration on determination of ash content in algae and other biomass. Algal Research, 40, 101486.

Manimozhi, G., \& Srinivasan, P. (2018). Emotional Intelligence and Academic Achievement: A MetaAnalysis. American Journal of Educational Research, 21(2), 179-181 
Mensih, M., Ibrahim, F., \& Hassan, N. (2021). Hubungan Antara Motivasi Pencapaian, Kecerdasan Emosi Dan Ketahanan Diri Dalam Kalangan Mahasiswa Kerja Sosial. e-Bangi, 18(1).

Mohd Nasir Rayung, Abdul Said Ambotang dan Mohd Yusof Abdullah. (2018). Pengaruh Kecerdasan Holistik Terhadap Kemenjadian Pelajar Tingkatan Enam di Sabah. Jurnal Kesidang, 3(1).

Muhamad, N., Hussin, N. L., \& Zokri, M. F. M. (2020). Hubungan Komitmen Organisasi, Motivasi Pekerja Dan Kecerdasan Emosi Pekerja Terhadap Produktiviti Kerja. Journal of Business Innovation, 5(1), 72.

Nazri, N., \& Salamuddin, N. (2019). Ketahanan mental dan kecerdasan emosi dalam kalangan pelajar. Jurnal Sains Sukan \& Pendidikan Jasmani, 8(2), 8-18.

Nordin, T.A. (2017). Pendidikan Sesuatu Pemikiran Semula. Kuala Lumpur: Dewan Bahasa dan Pustaka.

Prakas Rao (2019). Hubungan Kecerdasan Pelbagai, Gaya Pembelajaran dan Pencapaian Akademik Guru Pelatih. Jabatan Penyelidikan dan Inovasi Profesionalisme Keguruaan: Institut Pendidikan Guru, Kampus Perempuan Melayu, Melaka.

Qaiser Suleman, Ishtiaq Hussain, Makhdoom Ali Syed, Rashida Parveen, Ishrat Siddiqa Lodhi \& Ziarab Mahmood. (2019). Association between emotional intelligence and academic success among undergraduates: A cross-sectional study in KUST, Pakistan.

Razali, M. S. M., \& Raop, N. A. (2019). Mengenalpasti Faktor-Faktor Yang Mempengaruhi Pencapaian Akademik Pelajar Sarjana Muda Psikologi, Kolej Universiti Islam Melaka (KUIM). Jurnal Sains Sosial@ Malaysian Journal of Social Sciences, 3(1), 77-87.

Rifiana, A. J. (2015). Hubungan Antara Motivasi Instrinsik Dan Ekstrinsik Dengan Prestasi Belajar Mata Kuliah Askeb Ii (Persalinan) Mahasiswa D4 Bidan Pendidik Universitas Nasional. Jurnal Teknologi, 18(2), 103-112.

Rohaizad, Nor \& Rabi, N \& Ghazali, N \& Wahab, N \& Azlina, Kosnin. (2018). Relationship Between Emotional Intelligence and Parenting Style On Student Academic Achievement At Hulu Terengganu District. Jurnal Sains Humanika UTM, 58(1).

Rona, R., \& Yugal, K. K. (2017). Emotional Intelligence and Emotional Maturity and their relationship with Academic Achievement of College Students in Sikkim. International Journal of Education and Psychological Research (IJEPR), 7, 80-88.

Sahrai, D. (2016). Ethnographic insights into health literacy as social practice in vulnerable families in Switzerland. European Journal of Public Health, 26.

Shuhairy Norhisham, Mohd Zakwan Ramli, Marlinda Abdul Malek, Baizura Hamid, Nursyadzatul Tasnim Roslin, Mohd Eqwan Mohd Roslan \& Mohd Firdaus Mohd. (2018). Influence of project type, location, and area towards construction delay: A review on significance level of delay factors. UNITEN Scholarly Publication.

Strongman, K. T. (2018). Emotional intelligence and the construction and regulation of feelings. Applied and Preventive Psychology, 4(3), 197-208.

Sulaiman, M., Al Hamdani, M. D., \& Aziz, A. (2018). Emotional Spiritual Quotient (Esq) Dalam Pembelajaran Pendidikan Agama Islam Kurikulum 2013. Jurnal Penelitian Pendidikan Islam, [SL], 6(1), 77-110.

Talib, N. H. F., Bani Hidayat, M. S., \& Ab. Halim, T. (2017). Program Pengajian Tahfiz dan Asas Penawarannya di Politeknik: Satu Sorotan. Tinta Artikulasi Membina Ummah, 3, 1-13.

Wirawan, H., Tamar, M., \& Bellani, E. (2019). Principals' leadership styles: the role of emotional intelligence and achievement motivation. International Journal of Educational Management.

Yahaya, A., Boon, Y., \& Abdul, A. H. (2010). Kecerdasan emosi dan hubungannya dengan pencapaian akademik dan tingkahlaku pelajar. Journal of Science \& Mathematics Education, 117.

Ying, N. G. (2017). Hubungan Kecerdasan Emosi Dan Prestasi Kerja Dalam kalangan guru SJKC daerah Kota Tinggi. Thesis Sarjana. Universiti Teknologi Malaysia.

Zainuddin, J. (2017). Impact of Emotional Intelligence on Academic Achievement of English Language Learners. Journal of Social Sciences and Humanities. 